\title{
Diversity, Abundance, and Evolutionary Dynamics of Pong-like Transposable Elements in Triticeae
}

\author{
Dragomira N. Markova ${ }^{1, *}$ \\ Roberta J. Mason-Gamer ${ }^{1}$ \\ ${ }^{1}$ Department of Biological Sciences, University of Illinois at Chicago, M/C 067, 840 West \\ Taylor Street, Chicago, IL 60607, USA \\ *Corresponding author: markova@ucdavis.edu \\ Present address: Department of Plant Sciences (mail stop 3), 151 Asmundson Hall, \\ University of California, Davis, California 95616. Phone: +1 773-425-5539
}

3 tables, 7 figures, 3 supplementary tables 


\begin{abstract}
Pong-like elements are members of the PIF/Harbinger superfamily of DNA transposons that has been described in many plants, animals, and fungi. Most Pong elements contain two open reading frames (ORFs). One encodes a transposase (ORF2) that catalyzes transposition of Pong and related non-autonomous elements, while the function of the second is unknown. Little is known about the evolutionary history of Pong elements in flowering plants. In this work, we present the first comprehensive analysis of the diversity, abundance, and evolution of the Pong-like transposase gene in the genomes of 21 diploid species from the wheat tribe, Triticeae, and we present the first convincing evidence of horizontal transfer of nuclearencoded Pong elements in any organism. A phylogenetic analysis of nearly 300 Pong sequences based on a conserved region of the transposase domain revealed a complex evolutionary history of Pong elements that can be best explained by ancestral polymorphism, followed by differential evolutionary success of some transposase lineages, and by occasional horizontal transfer between phylogenetically distant genera. In addition, we used transposon display to estimate the abundance of the transposase gene within Triticeae genomes, and our results revealed varying levels of Pong proliferation, with numbers of transposase copies ranging from 22 to 92. Comparisons of Pong transposase abundance to flow cytometry estimates of genome size revealed that larger Triticeae genome size was not correlated with transposase abundance.
\end{abstract}

Key words: Pong-like, DNA transposon, Triticeae, phylogeny, transposon display, horizontal transfer 


\section{INTRODUCTION}

Transposable elements (TEs) are mobile genomic units with the ability to invade genomes through a process called transposition. They are abundant in all bacterial, plant, and animal genomes, and are major contributors to genome size and variability (Jiang et al., 2004, Lippman et al., 2004, Ma and Bennetzen, 2004, Lai et al., 2005, Morgante et al., 2005, Wang et al., 2006). Their ability to move to new genomic locations results in mutational activity and can alter the structure and the function of individual genes (Bennetzen, 2000, Biemont and Vieira, 2006). The proportion of TEs in plant genomes can range from approximately $10-12 \%$ in the Arabidopsis thaliana genome to $80 \%$ in the wheat, barley, and maize genomes (Arabidopsis Genome Initiative, 2000, Bennetzen, 2000, Meyers et al., 2001, Li et al., 2004, Paux et al., 2006, Charles et al., 2008, Wicker et al., 2009, Mayer et al., 2011).

Eukaryotic TEs have been divided into two broad classes according to their mode of transposition. Class I TEs (retroelements) transpose through an element-encoded mRNA intermediate; the DNA element itself is not mobilized. Class II TEs (DNA elements) transpose via a double-stranded DNA intermediate through a "cut and paste" mechanism whereby the element is excised and reinserted elsewhere in the host genome (Craig et al., 2002). Transposition of DNA elements requires the enzyme transposase (TPase), which catalyzes both excision and integration into a new genomic site. Class II elements that encode all functional products required for transposition are referred to as autonomous elements. Non-autonomous elements do not encode a functional transposase gene, but have retained the terminal sequences necessary for recognition and mobilization by the transposition machinery of related autonomous elements (Capy, 1998, Feschotte et al., 2002). All TE superfamilies contain both autonomous and non-autonomous elements. DNA elements are classified into superfamilies based on sequence similarity of the transposase gene, the element's terminal inverted repeats (TIRs), and the length of the target site duplications (TSDs) generated by the transposase upon inserting the element. Seventeen superfamilies of Class II TEs have been proposed so far in eukaryotes (Yuan and Wessler, 2011), with only five found in plant genomes (CACTA, Mutator, PIF/Harbinger, $h$ AT, and Tc1/mariner, Feschotte and Pritham, 2007, Yuan and Wessler, 2011). 
Pong elements belong to the PIF/Harbinger superfamily (Zhang et al., 2004), which consists of PIF and Pong-like elements. They were first discovered in the rice genome (Jiang et al., 2003), and members of this family have since been detected in the genomes of many plants, animals, and fungi (Zhang et al., 2004). Most Pong elements are approximately $5 \mathrm{~kb}$ long and appear to contain two open reading frames (ORFs). One encodes a transposase (TPase; ORF2), whereas the function of the other (ORF1) is still not clear (Figure 1A). ORF1 is thought to be involved in DNA binding and protein-protein interactions, as its domain codes a protein with weak similarity to the DNA-binding domain of $m y b$ transcription factors (Figure 1B) (Le et al., 2001, Zhang et al., 2001, Jiang et al., 2003). ORF2 contains a "DDE" motif (Figure 1C), a signature consisting of an amino acid triad identified in the transposases of most DNA transposon superfamilies (Rezsohazy et al., 1993, Jiang et al., 2003, Yuan and Wessler, 2011). The "DDE" motif consists of two aspartic acid (D) residues and a glutamic acid (E) residue interspersed among relatively well-conserved blocks of amino acids. The Pong transposase is implicated in the mobilization of miniature-Ping (mPing), an active, nonautonomous group of miniature inverted-repeat transposable elements (MITEs) (Jiang et al., 2003, Kikuchi et al., 2003, Nakazaki et al., 2003). The rice mPing family is the first actively transposing MITE discovered in any organism (Jiang et al., 2003). In rice, mPing copies are preferentially inserted into single-copy genomic regions (Jiang et al., 2003), and insertions into promoter regions can directly affect gene regulation and function (Naito et al., 2006). Thus mPing and Pong elements play important roles in the evolution of plant genes and genomes (Bureau and Wessler, 1992, 1994a, b, Bureau et al., 1996, Zhang et al., 2000).

Little is known about the diversity, abundance, and evolutionary history of Pong elements in flowering plants. Zhang et al. (2004) were the first to look at the distribution and evolution of Pong-like transposases in plants and animals, and they identified an abundance of Pong ORF2 fragments in a wide range of eukaryotic species. Phylogenetic analyses of 36 Pong-like transposase fragments revealed that Pong elements are ancient and widespread in plants, including both monocotyledons and dicotyledons (Zhang et al., 2004). These results were later confirmed by Yuan and Wessler (2011) when they examined the distribution of the PIF/Pong superfamily of TEs among others along 50 major eukaryotic lineages and found representatives from this superfamily in 35 out of 50 eukaryotic lineages. Phylogenetic analyses of Pong ORF2 sequences from bamboo species pointed to a complex evolutionary 
history of Pong elements, including the possibility of horizontal transfer (HT) between distinct bamboo species, although no conclusive evidence of HT was presented (Zhong et al., 2010).

In this work, we examined the distribution and evolution of Pong-like TEs in the genomes of 21 diploid species from the wheat tribe, Triticeae. Triticeae, a pooid tribe with approximately 30 genera and 300-400 species (Löve, 1984), is well known primarily for its economically important members, such as wheat, barley, and rye. The economic importance of the tribe has made it the focus of intense genetic studies over the last few decades. For example, cultivated wheats (Triticum) are among the most well studied models of genome evolution in the plant kingdom. The Triticeae genome is large and complex, with approximately 70-80\% composed of TEs (Li et al., 2004, Paux et al., 2006, Charles et al., 2008, Wicker et al., 2009, Mayer et al., 2011).

We performed a phylogenetic analysis of 297 Pong sequences based on a 520-bp region of the conserved transposase domain surrounding the "DDE" motif, and we identified 297 distinct transposase sequences. Of these, 51 were identified as "potentially functional" transpose sequences, i.e., those with no frameshifting indels or stop codons. Most of these revealed a signal of negative selection, indicating that the ORF2 is under purifying selection, consistent with the characteristics of a functional gene. The Pong transposase phylogeny revealed a complex evolutionary pattern of this region that can be best explained by ancestral polymorphism, followed by differential evolutionary success of some transposase lineages, and by occasional HT between genera. We also analyzed the abundance of the Pong transposase gene in Triticeae genome using a PCR-based technique called transposon display (TD), and we found varying levels of Pong proliferation in different genomes, with numbers of transposase copies ranging from 22 to 92 . Comparisons of Pong transposase abundance to previously-published flow cytometry estimates of genome size revealed that larger Triticeae genome size was not correlated with Pong transposase abundance.

\section{MATERIALS AND METHODS}

\subsection{Plant material}


A total of 22 accessions representing 21 species from 16 Triticeae genera were selected for analyses (Table 1). In order to avoid the potentially confounding phylogenetic effects of auto- and allopolyploidy, only diploid taxa were chosen. All accessions were obtained from the USDA and have associated chromosome counts. We included multiple accessions from Pseudoroegneria (bluebunch wheatgrass) and Hordeum (wild barley), the parental genome donors of North American allotetraploid Elymus species (Dewey, 1983a, 1983b, 1985, Mason-Gamer, 2001, Mason-Gamer et al., 2002, Helfgott and Mason-Gamer, 2004), which will be applicable to future studies of Pong-like transposon dynamics in allopolyploid genomes. An additional 20 Pong transposase sequences from 9 Poaceae genera and two Triticum species (Table 2) were obtained from Genbank and included in phylogenetic analyses.

\subsection{Amplification of the Pong transposase}

The conserved region of the transposase domain, corresponding to approximately $520 \mathrm{bp}$ in the majority of our samples, was amplified using degenerate PCR primers (Pong-for: GGCWCCATYGAYTGTATGCAC, and Pong-rev: YTCGTCYTCVACYATCATRTTGTG; Figure 1C) (Zhong et al., 2010). These primers are anchored in two highly conserved amino acid residue motifs (GTIDCMH and NMIVEDE respectively) of the transposase gene. Amplifications were carried out in $10 \mu \mathrm{l}$ reactions containing $50 \mathrm{ng}$ of genomic DNA, 10x PCR buffer, $0.2 \mathrm{mmol} / \mathrm{L}$ of primer pair, 0.5 units of Taq polymerase (Sigma), $0.2 \mathrm{mmol} / \mathrm{L}$ of dNTPs each, $1.5 \mathrm{mmol} / \mathrm{L} \mathrm{MgCl}_{2}$. The PCR amplification conditions were as follows: 2 min of DNA denaturation at $94{ }^{\circ} \mathrm{C}$, followed by 35 cycles of $30 \mathrm{~s}$ at $94^{\circ} \mathrm{C}, 60 \mathrm{~s}$ at $55^{\circ} \mathrm{C}$, and $45 \mathrm{~s}$ at $72^{\circ} \mathrm{C}$. The last cycle was followed by a 10 min final extension at $72{ }^{\circ} \mathrm{C}$.

\subsection{Cloning, sequencing and sequence alignment}

All PCR products were cloned prior to sequencing. Three PCR reactions were run for each cloning reaction to counter the potential effects of PCR drift (Wagner et al., 1994). PCR products from replicated reactions were isolated on $1 \%$ agarose gels, combined and purified 
on columns (Qiagen). Cleaned products were cloned into pGEM-T Easy vectors (Promega) and transformed into E.coli JM109 competent cells (Promega) according to the manufacturer's instructions, except that all reactions were halved. Positive (white) colonies containing the insert were subjected to PCR reactions as described above. The resulting fragments were cleaned with $0.2 \mu \mathrm{l}$ exonuclease and $0.4 \mu \mathrm{l}$ shrimp alkaline phosphatase, and sequenced in both directions with the PCR primers on an ABI 377 automated sequencer (Applied Biosystem). A minimum of 24 clones per sample were sequenced, including no more than 8 clones per cloning reaction, in order to evaluate intra-individual transposase diversity. Sequence identification was assessed by comparison with rice and bamboo ORF2 sequences in GenBank via the BLAST search algorithm (Altschul et al., 1990). The position of the "DDE" motif was predicted by comparison of a reduced set of aligned Triticeae sequences to the corresponding "DDE" motif of the first identified Pong element in rice (Jiang et al., 2003) (GenBank accession number BK000586). The nucleotide sequences of Pong-like transposases were aligned using CLUSTALW (Thompson et al., 1994) with default parameters, and then manually adjusted in MacClade 4.08 (Maddison and Maddison). The first alignment consisted only of sequences with no frameshifting indels or stop codons, so that the reading frame indicated in Zhong et al. (2010), could be used to aid in the alignment. The remaining sequences were then added to the initial alignment and all insertions and deletions were adjusted accordingly. Duplicate and nearly-duplicate sequences from within individuals (i.e., those that differed by $1 \mathrm{bp}$ representing potential Taq errors) were excluded based on the consensus sequence. However, 1-bp mutations from different cloning reactions that were detected in at least two sequences were considered. All sequences were deposited in the NCBI GenBank database (accession numbers KT252570-KT252866).

\subsection{Phylogenetic analyses}

Phylogenetic analyses of the conserved transposase region in Triticeae were performed on a region of approximately $520 \mathrm{bp}$. We generated 3 data sets for phylogenetic analyses. The first data set consisted of 51 transposase sequences with no frameshifting indels or stop codons (reduced data set). These sequences are provisionally considered to be functional, but this is highly speculative because we do not have the entire gene sequence, and because 
missense mutations leading to loss of function would not have been detected. The second data set included the reduced data set along with 20 additional ORF2 fragments from 9 additional Poaceae genera and two additional Triticum species (Table 2), and the third data set contained all 297 transposase sequences that we generated (complete data set excluding duplicate and nearly duplicate sequences from within individuals). Pairwise sequence distances were calculated from the multiple alignment using PAUP* 4.0b10 (Swofford, 2003). Phylogenies were estimated using maximum parsimony (MP) and maximum likelihood (ML). Parsimony analyses were conducted with PAUP* v.4.0b10 (Swofford, 2003) with heuristic searches. The parsimony bootstrap method, with 1000 replicates with heuristic search, was used to estimate the robustness of the clades (Felsenstein, 1985) (tree not shown). For ML analysis, the appropriate model of sequence evolution was determined by jModelTest (Posada and Crandall, 1998, Posada, 2008, 2009) and the corrected Akaike information criterion (Posada and Buckley, 2004). The selected models were implemented in the Mac OS X version of GARLI v.0.95 (Zwickl, 2006) for analysis. Following the recommendations of the author, multiple (50) analyses with random starting tree topologies were performed for each data set. Runs were set for an unlimited number of generations, and automatic termination following 10,000 generations without a significant change in topology. Bootstrap support for each tree was estimated using GARLI based on 100 ML bootstrap replicates with the same options used to generate the ML tree.

\subsection{Sequence variability and evolution}

The number of synonymous $(d \mathrm{~S})$ and non-synonymous $(d \mathrm{~N})$ substitution rates were estimated and compared $(d \mathrm{~N} / d \mathrm{~S})$ for the 51 transposase sequences with no frameshifting indels or stop codons to test for purifying selection. Accordingly, $d \mathrm{~N} / d \mathrm{~S}$ ratios near 1 reflect neutral sequence evolution, ratios less than 1 indicate negative or purifying selection, corresponding to high selective constraints, and values greater than 1 indicate positive selection, generally suggesting adaptive evolution. After removing one sequence (Agropyron cristatum 7) that was identical to another to avoid division by zero, $d \mathrm{~N} / d \mathrm{~S}$ ratios and codon based Z-tests were calculated through the modified Nei and Gojobori (1986) method with the Jukes-Cantor correction, implemented in MEGA v.5.0 (Tamura et al., 2011). 


\subsection{Pong transposase transposon display}

We used TD (detailed protocol and applications can be found in Casa et al., 2004) to examine the abundance of the Pong transposase gene in Triticeae genomes. Transposon display is a modification of the amplified fragment-length polymorphism (AFLP) technique (Vos et al., 1995), where genomic DNA is digested with a frequent-cutting restriction enzyme (RE), followed by the ligation of adapters to the digested fragments, and used as template for PCR reactions. One primer anchors in the area of the adapter and the other, which is fluorescently labeled, anchors near the end of the Pong transposase gene (Figure 1D; Figure 2). All DNA fragments that are visualized on the TD gel have an adapter primer at one end and a Pong element at the other end, and vary in length according to the location of the nearest RE site.

We digested approximately $450 \mathrm{ng}$ of genomic DNA to completion with 2 units of MseI (New England Biolabs, Ipswich, Ma) in a total volume of $40 \mu \mathrm{l}$ for $3 \mathrm{~h} 30 \mathrm{~min}$ at $37^{\circ} \mathrm{C}$ in NEB4 reaction buffer supplied by the manufacturer. Adapters (Table 3) were ligated to the digested DNA by adding $10 \mu \mathrm{l}$ of a mix containing $25 \mathrm{pmol}$ of forward and reverse MseI adapters, $5 \mu \mathrm{g}$ BSA, and 1 Weiss unit T4 DNA ligase (New England Biolabs, Ipswich, Ma) in 5x T4 DNA ligase buffer. The ligation reactions were incubated for $3 \mathrm{~h}$ at $37^{\circ} \mathrm{C}$. The quality of the DNA digestion was assessed by running $15 \mu$ of the restriction/ligation reaction on $0.8 \%$ agarose gels. The remaining reactions were diluted fourfold with $0.1 \mathrm{x}$ TE buffer and incubated overnight at $4{ }^{\circ} \mathrm{C}$.

The ligated DNA was amplified in a primary (preselective) PCR reaction using a primer complementary to the MseI adapters, and a primer (Pong_PSA) derived from a highly conserved amino acid block of residues (HNMIVEDE) near the end of the Pong transposase gene (Figure 1D; Table 3). All PCR amplifications were carried out in a $20 \mu 1$ reaction mixture containing $3 \mu \mathrm{l}$ of the diluted restriction and ligation reaction, 8 pmol of each primer, 10x PCR buffer, $0.2 \mathrm{~m} M$ dNTPs, $1.5 \mathrm{~m} M \mathrm{MgCl}_{2}$, and $0.4 \mathrm{U}$ Taq polymerase (Sigma). The PCR amplification conditions were: 5 min of DNA denaturation at $95^{\circ} \mathrm{C}$, followed by 35 cycles of $30 \mathrm{~s}$ at $95{ }^{\circ} \mathrm{C}, 45 \mathrm{~s}$ at $55^{\circ} \mathrm{C}$ and $60 \mathrm{~s}$ at $72{ }^{\circ} \mathrm{C}$. The last cycle was followed by a 10 min final extension at $72{ }^{\circ} \mathrm{C}$. The results of the preselective amplification were checked 
by running $10 \mu \mathrm{l}$ of each PCR reaction on $1.2 \%$ agarose gels stained with ethidium bromide. The remaining reactions were diluted 20 -fold with $0.1 \mathrm{x}$ TE buffer.

Approximately 60-70 ng of the primary PCR product were used as the template for a secondary (selective) PCR amplification. This reaction was carried out as above, except that the $M s e \mathrm{I}+\mathrm{N}(\mathrm{N}=\mathrm{A}, \mathrm{T}, \mathrm{C}$ or $\mathrm{G})$ primer was used in a combination with 4 pmol of Pong_SA (Figure 1D; Table 3) primer that was fluorescently labeled with the 6-FAM dye (Invitrogen), and the $\mathrm{MgCl}_{2}$ concentration was reduced to $1.5 \mathrm{mM}$. The following “touchdown” PCR protocol was used for all amplifications: $94{ }^{\circ} \mathrm{C}$ for $5 \mathrm{~min}$; 11 cycles of $94{ }^{\circ} \mathrm{C}$ for $30 \mathrm{~s}, 69^{\circ} \mathrm{C}$ for $60 \mathrm{~s},-0.7^{\circ} \mathrm{C}$ per cycle, $72{ }^{\circ} \mathrm{C}$ for $45 \mathrm{~s} ; 24$ cycles of $94{ }^{\circ} \mathrm{C}$ for $30 \mathrm{~s}$, $62{ }^{\circ} \mathrm{C}$ for $60 \mathrm{~s}, 72{ }^{\circ} \mathrm{C}$ for $45 \mathrm{~s}$; and a final cycle at $72{ }^{\circ} \mathrm{C}$ for $10 \mathrm{~min}$. The secondary PCR products were resolved on an ABI 377 (Applied Biosystems, Foster city, CA). A total of 0.3 $\mu l$ of each secondary PCR product was loaded into a 48 -well plate. A size standard was prepared by mixing $0.5 \mu \mathrm{l}$ of ROX-labeled sizing ladder (MapMarker® BioVentures, TN, USA) containing fragments ranging from 50 to $1000 \mathrm{bp}$ with $2.5 \mu 1$ of formamide and then adding the total $3 \mu \mathrm{l}$ of the mix to each sample in the 48 -well plate. The samples were then denatured at $95{ }^{\circ} \mathrm{C}$ for $5 \mathrm{~min}$., placed on ice, and $0.8 \mu \mathrm{l}$ of the mixture was loaded onto a $5 \%$ denaturing (6M urea) acrylamide:bisacrylamide (19:1) gel in 1x TBE and run with the GeneScan_GS_R36_2400D run module.

Genotyper Software v. 2.0 (Applied Biosystems, Foster city, CA) was used to analyze the ABI 377 electropherograms. The software estimates the size of the fluorescent peaks by comparing their mobility to the known sizes of the fragments in the ROX sizing ladder. We included fragments with a peak height of 150 and above relative fluorescence units (rfu) in subsequent analyses. To ensure that the TD patterns are reproducible, we repeated the whole procedure three times for each sample, and only fragments that appeared in the three replicates were scored and counted towards the total number of transposase fragments in each individual. Because of the possibility that some fragments might co-migrate, we performed four selective amplifications, each with an MseI selective primer that had a further extension of one nucleotide (see above), thus breaking the total pattern into four subpatterns. The total number of Pong transposase copies in each sample was estimated by counting all the bands generated using the four primer combinations. 


\subsection{Cloning and sequencing of transposon display fragments}

To confirm that the PCR fragments generated by TD are indeed Pong transposase sequences, we sequenced the secondary PCR products of $P$. spicata and Triticum monococcum (Table 1). We chose to clone these samples because they represented much of the Pong insertion site variation observed among species. We used the same PCR reaction conditions as described above, except that the selective primer, Pong_SA, was not fluorescently labeled. All PCR products were cloned as described earlier, and 25-30 clones from each sample were sequenced.

\section{RESULTS}

\subsection{Isolation and characterization of Pong-derived transposases}

PCR amplifications yielded a single band of approximately $520 \mathrm{bp}$ for all samples, with two exceptions. There were two bands in Peridictyon sanctum (420 bp and $520 \mathrm{bp}$, labeled "S" and "L" respectively in Figures 3-5), with the shorter band distinguished by having a $109 \mathrm{bp}$ deletion from position 226 to 335 of the consensus sequence alignment. There were also two bands in Crithopsis delileana (520 bp and $550 \mathrm{bp}$ ), with the latter harboring a $32 \mathrm{bp}$ insertion starting at position 24 of the consensus alignment. Sequence comparisons of Triticeae representatives and other members of the Poaceae (Figure 1C) revealed a highly conserved structure of the sequenced portion of the ORF2 domain, with the first $\mathrm{D}$ of the conserved "DDE" motif at position 4, the second $\mathrm{D}$ at position 94, and the $\mathrm{E}$ at position 130 of the consensus amino acid sequence, each surrounded by relatively well conserved amino acid blocks.

Of the 500 sequenced fragments, 297 were unique (complete data set), indicating the presence of multiple distinct TPases in each species. All sequences contained the "DDE" motif, but otherwise, significant heterogeneity was found within individuals, and each taxon was represented by a set of nonredundant clones. Of the 297 nonredundant sequences, 246 had frameshifting indels or stop codons, and thus are probably not functional. The remaining 51 fragments were aligned and used to generate the phylogenetic tree in Figure 3 (reduced 
data set). A phylogenetic analysis of these fragments showed that they are derived from multiple evolutionary lineages which, given our speculation that these sequences might be functional, would indicate that multiple TPases have the potential to activate autonomous and related non-autonomous elements simultaneously within a genome.

\subsection{Sequence variation of Pong-like transposase sequences}

Pong ORF2 sequences in Triticeae showed 56.19-100\% nucleotide and $69.23-100 \%$ amino acid sequence identity for the reduced data set (51 fragments) and 47.68-100\% sequence identity for the complete data set (63.57-100\% aa sequence similarity) (data not shown). Identical and near-identical ORF2 fragments were shared across genus boundaries in four cases (marked with rectangles on Figure 5): A. cristatum 7 was identical to Taeniatherum caput-medusae 1 23; Pseudoroegneria libanotica 20 was identical to A. cristatum 15; A. cristatum 4 differed from T. caput-medusae 19 in one non-synonymous (Histidine↔ Arginine) substitution, and Pseudoroegneria tauri 15 differed from A. cristatum 17 by one synonymous substitution. Cross-material contamination was deemed unlikely to produce these findings because extensive precautions were taken during all lab manipulations. The highest level of divergence was between Thinopyrum bessarabicum 14 and Hordeum chilense 5 with $47.68 \%$ sequence similarity. Peridictyon sanctum exhibited the highest intra-individual sequence divergence; its most divergent ORF 2 fragments showed only 50.27\% identity. Comparisons among Pong fragments from Triticeae vs. other members of the grass family showed 55.78-87.69\% sequence identity, with the lowest similarity between $H$. chilense 20 and Brachypodium distachyon 5 (55.78\%).

\subsection{Phylogeny of Pong-like transposases}

Maximum parsimony topologies (not shown) were in general accordance with the ML topologies; however, there was more resolution and support in the ML trees. Given the difficulties of finding an outgroup, we used the mid-point rooting method (Farris, 1972) for all of the phylogenetic trees. The position of the root is unknown, and depending on the rooting method, the number and relationships among main Pong groups can change. We 
could not use Pong sequences from grasses outside the wheat tribe to root the tree, because the root of the Pong element tree appears to predate the origin of the tribe (i.e., some Pong elements from within the Triticeae are more closely related to elements from outside of the tribe than they are to other elements within the tribe; see also Zhang et al., 2004, Zhong et al., 2010). In previous studies of Pong-like evolution in bamboo and in other angiosperms, a fungal sequence from the closely related transposon family PIF ( $P$-Instability Factor) was used as outgroup (Zhang et al., 2004, Zhong et al., 2010) (GenBank accession number AC068564). However, we decided that this choice was not appropriate for our data given a high sequence divergence and thus the possibility of increased homoplasy.

\subsubsection{Phylogeny of reduced data set}

The first data set contained 51 Triticeae sequences with no frameshifting indels or stop codons. In the best topology (Figure 3; - $\operatorname{lnL}=5966.02404$ ) most clades received strong ML bootstrap support. All Triticeae ORF2 sequences form four main groups (I-IV in Figure 3). Group I was weakly supported (bootstrap value < 50\%) and contained two weaklysupported subgroups (IA and IB). Subgroup IA consisted of sequences from Australopyrum velutinum and $P$. spicata. In the reduced data set $P$. spicata was represented by only one sequence that did not include frameshifting indels and/or stop codons from the total 20 nonredundant clones that we sequenced. Subgroup IB contained sequences from $H$. chilense and $A$. velutinum.

Within group II (99\% bootstrap), two subgroups (labeled IIA and IIB) were identified with 79 and $84 \%$ support. Subgroup IIA included sequences from Psathyrostachys fragilis, Hordeum bogdanii, and from $H$. chilense, which was also represented in subgroup IB. Subgroup IIB contained sequences from A. cristatum, Secale montanum, T. monococcum, and two T. caput-medusae individuals; all of these species except $S$. montanum, were also found in either subgroup IVA or IVB.

Group III was robustly supported (100\% bootstrap) and consisted of two Dasypyrum villosum sequences and one from $P$. sanctum. Peridictyon sanctum was also represented in subgroups IVA and IVB. Henrardia persica 16 was sister to the rest of group IV. The position of this sequence is uncertain and was represented by a polytomy in the MP tree. 
Group IV was split into two subgroups: IVA (weakly supported) included sequences from T. caput-medusae, C. delileana, Aegilops comosa, and P. sanctum, and subgroup IVB (92\% support), in which a sequence from $P$. sanctum was placed as sister to sequences from numerous Triticeae genera. Within this subgroup, A. cristatum 7 was identical to T. caputmedusae 123 and Pseudoroegneria tauri 15 differed from A. cristatum 17 by one synonymous substitution (marked with rectangles in Figure 3). The presence of identical or nearly-identical transposase fragments within distantly related genera is probably due to introgressive events, which will be discussed in more detail below.

\subsubsection{Phylogeny of Pong-like transposases in Poaceae}

These analyses included the reduced data set (used for Figure 3) along with 20 additional Pong ORF2 fragments from 9 Poaceae genera and two Triticum species (Table 2, Figure 4). All of these sequences were from GenBank (accession numbers are provided in Table 2), and had no frameshifting indels or stop codons. The best topology $(-\operatorname{lnL}=10904.59063$; Figure 4) was in general accordance with the tree from the reduced data set (Figure 3). None of the differences between these two topologies involved wellsupported relationships on either tree.

Sequences from grass genera outside the wheat tribe were placed in well defined and generally well supported groups along with Pong sequences from the wheat tribe. For instance, sequences from rice (Oryza sativa), corn (Zea mays), and purple false brome (Brachypodium distachyon) were placed with $H$. chilense and A. velutinum sequences in Group I (weak bootstrap support). Two B. distachyon sequences and one from bamboo (Chimonobambusa tumidissinoda) were clustered with three Triticeae sequences in Group III with strong support ( $88 \%$ bootstrap). Sequences from three bamboo genera (Phyllostachys, Pleioblastus, and Semiarundinaria) formed a moderately supported subgroup with a sequence from Triticum turgidum (62\% bootstrap, Figure 4).

\subsubsection{Phylogeny of complete data set}


The third data set included 297 non-redundant Pong-like ORF2 sequences from all 22 accessions (Table 1; complete data set), including the presumably non-functional copies with frameshifting indels and/or stop codons. The best topology $(-\ln L=26969.88581$;

Figure 5) revealed at least six main groups of Pong transposases in Triticeae (A-F in Figure 5). Group B (100\% bootstrap) contained sequences from all samples that we analyzed and was divided into two subgroups (B1 and B2; 82 and 71\% BS respectively). Group D (82\% BS) was the second most diverse and was divided into subgroups D1 and D2 (82\% BS for D2). Group D was represented by sequences from all samples except five $(H$. chilense, $A$. velutinum, S. montanum, D. villosum, and Eremopyrum bonaepartis). Groups A, C, and E (all 100\% BS) were less complex and included sequences from fewer taxa (Figure 5). Group F (weakly supported) included two A. velutinum clusters with $100 \%$ bootstrap support.

Four pairs of ORF2 sequences from distinct genera were identical or nearly so (marked with rectangles on Figure 5). In subgroup D2, three pairs were detected: A. cristatum 7 and T. caput-medusae 1 23; P. libanotica 20 and A. cristatum 15; and P. tauri 15 and A. cristatum 17. In subgroup B2, there was a single pair: A. cristatum 4 and T. caputmedusae 119.

\subsection{Detecting signatures of selection in the transposase domain using $\mathrm{d} N / \mathrm{d} S$ ratios}

It is expected that a currently or recently functional gene will have been under strong selective pressure to maintain its coding sequence. $d \mathrm{~N} / d \mathrm{~S}$ comparisons of 50 transposases with no frameshifting indels or stop codons showed a dominant signal of purifying selection $(d \mathrm{~N} / d \mathrm{~S}<1)$ with an overall $d \mathrm{~N} / d \mathrm{~S}$ ratio of 0.326 (supplementary Table 1 and 2 , Supplementary Material online). The Z-test p-values were above the cutoff of 0.05 for some ORF2 sequence comparisons, evidencing neutrality, mostly due to a very low number of substitutions between the sequences involved (insufficient number of substitutions produce statistically not valuable $d \mathrm{~N} / d \mathrm{~S}$ estimations; Casola et al. (2007) (in red in supplementary Table 3, Supplementary Material online). For example, A. cristatum 15 differed from $P$. tauri 15 by two synonymous and one non-synonymous substitution $(\mathrm{p}=0.282)$; and from $P$. tauri

23 and $P$. tauri 25 by two synonymous and two non-synonymous substitutions $(\mathrm{p}=0.422$ and $\mathrm{p}=0.911$, respectively). Taeniatherum caput-medusae 123 differed from A. cristatum 17 by 
three synonymous and three non-synonymous substitutions $(\mathrm{p}=0.871)$. However, our results indicate that purifying selection is acting on most transposase sequences, consistent with characteristics of a functional gene.

\subsection{Cloning of transposon display fragments}

To confirm that the amplified fragments visualized with TD indeed correspond to the Pong transposase gene, we cloned and sequenced 30 secondary PCR products from T. monococcum and 25 PCR products from $P$. spicata. All but one corresponded to the Pong transposase gene and contained the sequence downstream of the HNMIVEDE amino acid motif. One clone was excluded from analysis because it was a PCR recombinant. The other 54 sequence fragments were aligned and ranged in size from $88 \mathrm{bp}$ to $405 \mathrm{bp}$. We detected one conserved domain, approximately 55 amino acids downstream of Pong_SA, which consisted of five amino acids (DLV(I)EH) (Figure 1D). The sequenced transposase fragments were correlated in size with the bands obtained from the TD technique (data not shown). We matched all but four clones with their corresponding bands from the TD gel.

\subsection{Pong transposase abundance}

Transposon display analysis of 22 Triticeae accessions (Table 1) yielded a total of 1337 fragments ranging in size from 56 to $542 \mathrm{bp}$. The number of transposase copies detected per genome ranged from 22 (T. bessarabicum) to 92 (C. delileana and A. cristatum) (Figure 6). Triticeae genera show large differences in DNA content, ranging from $7.96 \mathrm{pg} / 2 \mathrm{C}$ in $P$. libanotica to $18.9 \mathrm{pg}$ in S. montanum (Bennett and Leitch, 2012; Table 1). We found a slight negative correlation between genome size and Pong transposase copy number $(r=-0.372$; $\mathrm{p}=0.14$ ) across 18 accessions, indicating that genome size alone does not explain Pong transposase abundance (Figure 7).

\section{DISCUSSION}


In this work, we isolated, cloned and sequenced approximately one-third of the DNA sequence encoding the transposase domain of Pong-like TEs in 21 diploid Triticeae species in order to (1) examine the sequence variability of this region within the tribe; (2) determine whether the existing Pong transposase lineages originated prior the origin of the tribe; and (3) identify possible introgression between distantly related species. We also analyzed the abundance of the Pong transposase gene in Triticeae genomes, and we performed comparative analysis to flow cytometry estimates of Triticeae genome size to determine whether larger genomes are correlated with higher Pong transposase abundance.

\subsection{Evolution of Pong-like elements in Triticeae}

All Triticeae genomes contain diverse transposase lineages. The existence of such divergent TE sequences in a single host genome has already been reported for other elements such as PIF (Zhou et al., 2010), mariner (Robertson and MacLeod, 1993), P (Clark and Kidwell, 1997), and Minos (Arca and Savakis, 2000), and is best explained by ancient episodes of element diversification in early ancestors, followed by vertical propagation.

All Pong topologies are consistent with the existence of diverse ancestral transposase lineages that were vertically transmitted. However, cases of identical and nearly identical transposase sequences in distantly related genera suggest that occasional horizontal transfer events also play an important role in the complex distribution of transposases in the tribe.

\subsubsection{Vertical transmission of Pong-like transposases}

Phylogenetic analyses of both the reduced and the complete data sets (Figures 3 and 5) reveal that multiple distinct lineages of Pong transposases coexist within single genomes. Both topologies show vertical transmission of multiple diverse ancestral transposase lineages, with some lineages experiencing differential evolutionary success. The wide representation of taxa in Groups B and D (Figure 5) suggests an extensive diversification of these transposases prior the origin of the wheat tribe (13-25 mya) (Gaut, 2002). The presence of all lineages from group $\mathrm{D}$ in all but five individuals may be attributed either to a loss from those five genomes, or to a sampling effect where the PCR technique did not detect all of the 
sequences. Lineages A, C, and E are represented in far fewer individuals (Figure 5); this may be due to differential evolutionary success of those lineages, and to stochastic losses.

However, the presence of these lineages in species derived from basal branches of the wheat tribe such as Psathyrostachys (Mason-Gamer et al., 2002, Escobar et al., 2011) indicates that the lineages were already present at the beginning of Triticeae radiation. The descendents of these ancestral lineages diverged during the diversification of the tribe, and some species appear to have lost them.

Given the "cut and paste" mechanism of DNA TEs, the creation of ancestral Pong paralogues could be explained by gene or chromosomal duplications, and/or by diversification of copies that rely on host machinery such as host DNA replication and gap repair following transposon excision (reviewed in Feschotte and Pritham, 2007). Duplication events have occurred during Poaceae evolution (Paterson et al., 2004, Kim et al., 2009), and the Triticeae have experienced various processes of genome diversification such as chromosomal rearrangements, ancient and recent polyploidization events, and segmental and gene duplications (Kellogg et al., 1996, Mason-Gamer, 2008, Mason-Gamer et al., 2010). Transposon content within a genome is a balance between transposition, TE sequence removal, and host responses. These processes are in turn affected by population processes, such as genetic drift and natural selection. It is reasonable to assume that some copies will be lost or retained within a genome, and that the retained copies have the potential to evolve differently in different genomes.

The analysis of 20 more ORF2 sequences from other Poaceae genera provides additional support for the ancient origin of most transposase lineages (Figure 4). ORF2 sequences from Triticeae grouped with Poaceae sequences in reasonably well-supported clades. The overall age of grasses has been estimated to be around 55-70 million years (Jacobs et al., 1999). The presence of sequences from very distant representatives such as corn, sorghum, rice, and bamboos in groups I and III in Figure 4, suggests that these lineages originated long ago, probably before the origin of grasses.

\subsubsection{Horizontal transfer of Pong-like transposases}


Past or ongoing HT also appears to have contributed to the distribution of Pong-like elements in Triticeae. This hypothesis is supported by pairs of identical and nearly-identical transposase fragments shared among genera in four cases (marked with rectangles in Figure 5). Diao et al. (2006) proposed that transposable elements are particularly prone to horizontal transfer due to their mobility and capacity to integrate into a host genome. However, only a handful of well-documented cases of HT of nuclear-encoded plant TEs have been detected so far (Diao et al., 2006). Our results provide the first convincing evidence of horizontal transfer of Pong elements in any organism.

Horizontal transfer of TEs can occur via vectors such as bacteria, fungi or sapsucking insects (Kondo et al., 2002, Shen et al., 2003), or through hybridization and introgression (transfer of genetic material from the genome of one species to the other via recurrent backcrossing of a hybrid with one of its parents). The transfer of TEs via hybridization might at first seem less likely to explain the observed relationships, because it requires hybridization of different Triticeae genera. However, the evolutionary history of the tribe has been extensively studied and among angiosperms, Triticeae grasses provide a particularly striking example of a group that does not evolve in a tree like manner (Kellogg et al., 1996, Mason-Gamer, 2001, Mason-Gamer et al., 2002, Helfgott and Mason-Gamer, 2004, Mason-Gamer, 2008, Mason-Gamer et al., 2010). Polyploids have long been suspected to serve as genetic bridges between diploid species (Kellogg et al. 1996), and if introgression is responsible for the sporadic distribution of these Pong transposases, it might proceed via polyploids.

There is no straightforward way to distinguish whether our results reflect vectormediated HT or hybridization without examination of the flanking regions of the TE and the identification of a common vector. However, selective constraints or vertical transmission can reasonably be ruled out as an explanation for the shared identical, or nearly identical sequences. It is highly unlikely that these transposase sequences diverged at the same time as their hosts and maintained near identity throughout the evolutionary history of the tribe, especially given that substitution rates of DNA TE ORF2s are in general higher than those of nuclear genes (Witherspoon, 1999, Lampe et al., 2003, Silva and Kidwell, 2004). Moreover, two of the four pairs of sequences (Pseudoroegneria libanotica 20 and A. cristatum 15; A. 
cristatum 4 and T. caput-medusae 1 19) contain presumably non-functional transposases with at least one stop codon present in their coding frame.

Although we can not generalize our results to other DNA transposons, we have obtained similar results in our investigation of PIF elements (unpublished), another family of DNA transposons in the $P I F /$ Harbinger superfamily. Both $P I F$ and Pong TEs show similar evolutionary trajectories within the wheat tribe, best explained by descent from diverse ancestral transposases and occasional HT events between genera. Compared to Pong, however, the expansion of PIF elements within Triticeae seems to be more recent. Most PIF sequences appear to be relatively young, with a maximum sequence divergence of $27.5 \%$, compared to a maximum of $52.35 \%$ divergence for Pong elements from the same host plants (data not shown). However, it is also possible that we have amplified only a subset of existing PIF elements, or that they evolve more slowly.

\subsection{Detecting signatures of selection in 50 Pong-like transposase sequences}

To examine whether the Triticeae Pong transposases represent functional genes, we performed interspecific pairwise sequence comparisons of $d \mathrm{~N} / d \mathrm{~S}$ ratios of the 50 transposase sequences with no frameshifting indels and/or stop codons. These sequences are considered to be potentially functional, but we acknowledge that this is a very preliminary assumption because we do not have the entire gene sequence, and because missense mutations leading to loss of function would not have been detected. Apart from few artifactual $d \mathrm{~N} / d \mathrm{~S}$ values caused by a very low number of substitutions between the sequences involved, our results reveal a dominant signal of negative selection (average values of $d \mathrm{~N} / d \mathrm{~S}$ of 0.326 ), indicating that the ORF2 domain is under purifying selection in Triticeae (or it was in the recent past). Our $d \mathrm{~N} / d \mathrm{~S}$ values for these 50 transposase fragments allow us to infer recent Pong activity in Triticeae, like transposition or mobilization of non-autonomous elements.

\subsection{Pong transposase abundance}

The five-fold variation in Pong transposase haplotypes within Triticeae genomes cannot be conclusively explained with the available data. Larger Triticeae genomes are not 
correlated with increased transposase abundance $(r=-0.377 ; p=0.14$; Figure 7$)$, closely mirroring Chia et al.'s (2012) analysis of more than 1300 TE families with respect to genome size for 27 lines of maize. Variations in the abundance of DNA transposons between closely related species has already been reported. For example, the CACTA DNA element Jorge accounts for only $0.03 \%$ of the Hordeum vulgare and H. spontaneum genomes, in contrast to 4.93\% of Aegilops tauschii genome (Middleton et al., 2013). The recently discovered transposon-like gene Revolver (Tomita et al., 2011) is found in extremely high copy numbers in the Triticeae species D. villosum and Secale sp. ( 20,000), and in T. monococcum $(\sim 10,000)$, while there are virtually no copies in the bread wheat genome (Triticum aestivum).

Variation in TE abundance has also been correlated with the effects of ecological stress. For example, Tomita et al. (2011) examined 161 T. dicoccoides accessions, representing 18 populations collected from various ecological conditions of soil, temperature, water availability, and altitude. They found high copy numbers of Revolver in strains collected from areas with high precipitation and average yearly temperature conditions around $20^{\circ} \mathrm{C}$, while strains collected from warmer areas with frequent hot dry monsoons contained only few hundred copies (Tomita et al., 2011). Comparable ecological analyses might help explain the variation in Pong transposase abundance in Triticeae genomes. As stated earlier, TE content within a genome depends on transposition and sequence removal via drift and natural selection. Even closely related species might differ in how they control TE proliferation, such as the strength of selection against TEs or the efficiency of epigenetic modification. As a result, opposing forces of TE proliferation and removal have the potential to create extensive variation within and between species, and enable lineages to diverge rapidly in TE content, as observed for Triticeae genomes.

\section{CONCLUSION}

Here we report the first comprehensive phylogenetic analysis of Pong-like TEs from the wheat tribe. We identified multiple distinct evolutionary lineages of Pong transposases, including some that appear to be currently or recently active, and we found convincing evidence of four independent cases of horizontal transmission of Pong transposases between 
phylogenetically distant genera. The overall evolutionary patterns are extremely complex, and the hypotheses that we propose to explain our results (ancestral polymorphism, stochastic loss and retention of Pong copies, different evolutionary success, and/or past and ongoing hybridization events) are not mutually exclusive.

\section{ACKNOWLEDGMENTS}

This work was supported by a National Science Foundation Grant (DEB-0426194) to Roberta J. Mason Gamer; and a Provost's Award, and an Elmer Hadley Research Award from the University of Illinois at Chicago to Dragomira N. Markova. We wish to thank Mary $\mathrm{V}$. Ashley for her corrections and valuable comments on the manuscript. 


\section{REFERENCES}

Altschul SF, Gish W, Miller W, Myers EW, Lipman DJ. 1990. Basic local alignment search tool. J Mol Biol. 215:403-410.

Arabidopsis Genome Initiative A. 2000. Analysis of the genome sequence of the flowering plant Arabidopsis thaliana. Nature 408:796-815.

Arca B, Savakis C. 2000. Distribution of the transposable element Minos in the genus Drosophila. Genetica 108:263-267.

Bennetzen JL. 2000. Transposable element contributions to plant gene and genome evolution. Plant Mol Biol. 42:251-269.

Biemont C, Vieira C. 2006. Genetics: junk DNA as an evolutionary force. Nature 443:521524.

Bureau TE, Ronald PC, Wessler SR. 1996. A computer-based systematic survey reveals the predominance of small inverted-repeat elements in wild-type rice genes. Proc Natl Acad Sci U S A. 93:8524-8529.

Bureau TE, Wessler SR. 1994a. Mobile inverted-repeat elements of the Tourist family are associated with the genes of many cereal grasses. Proc Natl Acad Sci U S A. 91:1411-1415.

Bureau TE, Wessler SR. 1994b. Stowaway: a new family of inverted repeat elements associated with the genes of both monocotyledonous and dicotyledonous plants. Plant Cell 6:907-916.

Bureau TE, Wessler SR. 1992. Tourist: a large family of small inverted repeat elements frequently associated with maize genes. Plant Cell 4:1283-1294.

Capy P, Bazin C, Higuet D and Langin T. 1998. Dynamics and evolution of transposable elements. Austin, Texas: Landes Biosciences.

Casa A, Nagel A, Wessler S. 2004. MITE display. In: Miller W, Capy P, editors. Mobile genetic elements. City Humana Press. p. 175-188.

Casola C, Lawing AM, Betran E, Feschotte C. 2007. PIF-like transposons are common in Drosophila and have been repeatedly domesticated to generate new host genes. Mol Biol Evol. 24:1872-1888.

Charles M, Belcram H, Just J, Huneau C, Viollet A, Couloux A, Segurens B, Carter M, Huteau V, Coriton O, et al. 2008. Dynamics and differential proliferation of transposable elements during the evolution of the B and A genomes of wheat. Genetics 180:1071-1086. 
Chia JM, Song C, Bradbury PJ, Costich D, de Leon N, Doebley J, Elshire RJ, Gaut B, Geller L, Glaubitz JC, et al. 2012. Maize HapMap2 identifies extant variation from a genome in flux. Nat Genet. 44:803-807.

Clark JB, Kidwell MG. 1997. A phylogenetic perspective on $P$ transposable element evolution in Drosophila. Proc Natl Acad Sci U S A. 94:11428-11433.

Craig N, Craigie R, Gellert M, Lambowitz A. 2002. Mobile DNA II. Washington, DC: American Society for Microbiology Press.

Dewey D. 1985. The Genomic system of classification as a guide to intergeneric hybridization with the perennial Triticeae. In: Gustafson JP, editor. Gene Manipulation in Plant Improvement: Springer US. p. 209-279.

Dewey D. 1983a. New nomenclatural combinations in the North American perennial Triticeae (Gramineae). Brittonia 35:30-33.

Dewey DR. 1983b. Historical and current taxonomic perspectives of Agropyron, Elymus, and related genera. Crop Sci. 23:637-642.

Diao X, Freeling M, Lisch D. 2006. Horizontal transfer of a plant transposon. PLoS Biol. 4:e5.

Escobar JS, Scornavacca C, Cenci A, Guilhaumon C, Santoni S, Douzery EJ, Ranwez V, Glemin S, David J. 2011. Multigenic phylogeny and analysis of tree incongruences in Triticeae (Poaceae). BMC Evol Biol. 11:181.

Farris JS. 1972. Estimating phylogenetic trees from distance matrices. Am Nat. 106:645-668.

Felsenstein J. 1985. Confidence limits on phylogenies: an approach using the bootstrap. Evolution 39:783-791.

Feschotte C, Jiang N, Wessler SR. 2002. Plant transposable elements: where genetics meets genomics. Nat Rev Genet. 3:329-341.

Feschotte C, Osterlund MT, Peeler R, Wessler SR. 2005. DNA-binding specificity of rice mariner-like transposases and interactions with Stowaway MITEs. Nucleic Acids Res. 33:2153-2165.

Feschotte C, Pritham EJ. 2007. DNA transposons and the evolution of eukaryotic genomes. Annu Rev Genet. 41:331-368.

Gaut BS. 2002. Evolutionary dynamics of grass genomes. New Phytol. 154:15-28. 
Helfgott DM, Mason-Gamer RJ. 2004. The evolution of north american Elymus (Triticeae, Poaceae) allotetraploids: evidence from phosphoenolpyruvate carboxylase gene sequences. Syst Bot. 29:850-861.

Holligan D, Zhang X, Jiang N, Pritham EJ, Wessler SR. 2006. The transposable element landscape of the model legume Lotus japonicus. Genetics 174:2215-2228.

Jacobs BF, Kingston JD, Jacobs LL. 1999. The origin of grass-dominated ecosystems. Ann Mo Bot Gar. 86:590-643.

Jiang N, Bao Z, Zhang X, Hirochika H, Eddy SR, McCouch SR, Wessler SR. 2003. An active DNA transposon family in rice. Nature 421:163-167.

Jiang N, Feschotte C, Zhang X, Wessler SR. 2004. Using rice to understand the origin and amplification of miniature inverted repeat transposable elements (MITEs). Curr Opin Plant Biol. 7:115-119.

Kellogg EA, Appels R, Mason-Gamer RJ. 1996. When genes tell different stories: the diploid genera of Triticeae (Gramineae). Syst Bot. 21: 321-347.

Kikuchi K, Terauchi K, Wada M, Hirano HY. 2003. The plant MITE mPing is mobilized in anther culture. Nature 421:167-170.

Kim C, Tang H, Paterson A. 2009. Duplication and divergence of grass genomes: Integrating the Chloridoids. Trop Plant Biol. 2:51-62.

Kondo N, Nikoh N, Ijichi N, Shimada M, Fukatsu T. 2002. Genome fragment of Wolbachia endosymbiont transferred to X chromosome of host insect. Proc Natl Acad Sci U S A. 99:14280-14285.

Lai J, Li Y, Messing J, Dooner HK. 2005. Gene movement by Helitron transposons contributes to the haplotype variability of maize. Proc Natl Acad Sci U S A. 102:9068-9073.

Lampe DJ, Witherspoon DJ, Soto-Adames FN, Robertson HM. 2003. Recent horizontal transfer of mellifera subfamily mariner transposons into insect lineages representing four different orders shows that selection acts only during horizontal transfer. Mol Biol Evol. 20:554-562.

Le QH, Turcotte K, Bureau T. 2001. Tc8, a Tourist-like transposon in Caenorhabditis elegans. Genetics 158:1081-1088.

Li W, Zhang P, Fellers JP, Friebe B, Gill BS. 2004. Sequence composition, organization, and evolution of the core Triticeae genome. Plant J. 40:500-511. 
Lippman Z, Gendrel AV, Black M, Vaughn MW, Dedhia N, McCombie WR, Lavine K, Mittal V, May B, Kasschau KD, et al. 2004. Role of transposable elements in heterochromatin and epigenetic control. Nature 430:471-476.

Löve A. 1984. Conspectus of the Triticeae. Feddes Repert. 95:425-521.

Ma J, Bennetzen JL. 2004. Rapid recent growth and divergence of rice nuclear genomes. Proc Natl Acad Sci U S A. 101:12404-12410.

Mason-Gamer RJ. 2008. Allohexaploidy, introgression, and the complex phylogenetic history of Elymus repens (Poaceae). Mol Phylogenet Evol. 47:598-611.

Mason-Gamer RJ. 2001. Origin of north american Elymus (Poaceae: Triticeae) allotetraploids based on granule-bound starch synthase gene sequences. Syst Bot. 26:757-768.

Mason-Gamer RJ, Burns MM, Naum M. 2010. Reticulate evolutionary history of a complex group of grasses: phylogeny of Elymus StStHH allotetraploids based on three nuclear genes. PLoS One 5:e10989.

Mason-Gamer RJ, Orme NL, Anderson CM. 2002. Phylogenetic analysis of North American Elymus and the monogenomic Triticeae (Poaceae) using three chloroplast DNA data sets. Genome 45:991-1002.

Mayer KF, Martis M, Hedley PE, Simkova H, Liu H, Morris JA, Steuernagel B, Taudien S, Roessner S, Gundlach H, et al. 2011. Unlocking the barley genome by chromosomal and comparative genomics. Plant Cell 23:1249-1263.

Meyers BC, Tingey SV, Morgante M. 2001. Abundance, distribution, and transcriptional activity of repetitive elements in the maize genome. Genome Res. 11:1660-1676.

Middleton CP, Stein N, Keller B, Kilian B, Wicker T. 2013. Comparative analysis of genome composition in Triticeae reveals strong variation in transposable element dynamics and nucleotide diversity. Plant J. 73:347-356.

Morgante M, Brunner S, Pea G, Fengler K, Zuccolo A, Rafalski A. 2005. Gene duplication and exon shuffling by helitron-like transposons generate intraspecies diversity in maize. Nat Genet. 37:997-1002.

Naito K, Cho E, Yang G, Campbell MA, Yano K, Okumoto Y, Tanisaka T, Wessler SR. 2006. Dramatic amplification of a rice transposable element during recent domestication. Proc Natl Acad Sci U S A. 103:17620-17625.

Nakazaki T, Okumoto Y, Horibata A, Yamahira S, Teraishi M, Nishida H, Inoue H, Tanisaka T. 2003. Mobilization of a transposon in the rice genome. Nature 421:170-172. 
Nei M, Gojobori T. 1986. Simple methods for estimating the numbers of synonymous and nonsynonymous nucleotide substitutions. Mol Biol Evol. 3:418-426.

Paterson AH, Bowers JE, Chapman BA. 2004. Ancient polyploidization predating divergence of the cereals, and its consequences for comparative genomics. Proc Natl Acad Sci U S A. 101:9903-9908.

Paux E, Roger D, Badaeva E, Gay G, Bernard M, Sourdille P, Feuillet C. 2006.

Characterizing the composition and evolution of homoeologous genomes in hexaploid wheat through BAC-end sequencing on chromosome 3B. Plant J. 48:463-474.

Posada D. 2008. jModelTest: phylogenetic model averaging. Mol Biol Evol. 25:1253-1256.

Posada D. 2009. Selection of models of DNA evolution with jModelTest. Methods Mol Biol. 537:93-112.

Posada D, Buckley TR. 2004. Model selection and model averaging in phylogenetics: advantages of akaike information criterion and bayesian approaches over likelihood ratio tests. Syst Biol. 53:793-808.

Posada D, Crandall KA. 1998. MODELTEST: testing the model of DNA substitution. Bioinformatics 14:817-818.

Rezsohazy R, Hallet B, Delcour J, Mahillon J. 1993. The IS4 family of insertion sequences: evidence for a conserved transposase motif. Mol Microbiol. 9:1283-1295.

Robertson HM, MacLeod EG. 1993. Five major subfamilies of mariner transposable elements in insects, including the Mediterranean fruit fly, and related arthropods. Insect Mol Biol. 2:125-139.

Shen Z, Denton M, Mutti N, Pappan K, Kanost MR, Reese JC, Reeck GR. 2003.

Polygalacturonase from Sitophilus oryzae: possible horizontal transfer of a pectinase gene from fungi to weevils. J Insect Sci. 3:24.

Silva JC, Kidwell MG. 2004. Evolution of $P$ elements in natural populations of Drosophila willistoni and D. sturtevanti. Genetics 168:1323-1335.

Swofford DL. 2003. Phylogenetic Analysis Using Parsimony (*and Other Methods). Sunderland (MA): Sinauer Associates.

Tamura K, Peterson D, Peterson N, Stecher G, Nei M, Kumar S. 2011. MEGA5: molecular evolutionary genetics analysis using maximum likelihood, evolutionary distance, and maximum parsimony methods. Mol Biol Evol. 28:2731-2739. 
Thompson JD, Higgins DG, Gibson TJ. 1994. CLUSTAL W: improving the sensitivity of progressive multiple sequence alignment through sequence weighting, position-specific gap penalties and weight matrix choice. Nucleic Acids Res. 22:4673-4680.

Tomita M, Okutani A, Beiles A, Nevo E. 2011. Genomic, RNA, and ecological divergences of the Revolver transposon-like multi-gene family in Triticeae. BMC Evol Biol. 11:269.

Vos P, Hogers R, Bleeker M, Reijans M, van de Lee T, Hornes M, Frijters A, Pot J, Peleman J, Kuiper M, et al. 1995. AFLP: a new technique for DNA fingerprinting. Nucleic Acids Res. 23:4407-4414.

Wagner A, Blackstone N, Cartwright P, Dick M, Misof B, Snow P, Wagner GP, Bartels J, Murtha M, Pendleton J. 1994. Surveys of gene families using polymerase chain reaction: PCR selection and PCR drift. Syst Biol. 43:250-261.

Wang W, Zheng H, Fan C, Li J, Shi J, Cai Z, Zhang G, Liu D, Zhang J, Vang S, et al. 2006. High rate of chimeric gene origination by retroposition in plant genomes. Plant Cell 18:17911802.

Wicker T, Taudien S, Houben A, Keller B, Graner A, Platzer M, Stein N. 2009. A wholegenome snapshot of 454 sequences exposes the composition of the barley genome and provides evidence for parallel evolution of genome size in wheat and barley. Plant J. 59:712722.

Witherspoon DJ. 1999. Selective constraints on $P$-element evolution. Mol Biol Evol. 16:472478.

Yuan YW, Wessler SR. 2011. The catalytic domain of all eukaryotic cut-and-paste transposase superfamilies. Proc Natl Acad Sci U S A. 108:7884-7889.

Zhang L, Dawson A, Finnegan DJ. 2001. DNA-binding activity and subunit interaction of the mariner transposase. Nucleic Acids Res. 29:3566-3575.

Zhang Q, Arbuckle J, Wessler SR. 2000. Recent, extensive, and preferential insertion of members of the miniature inverted-repeat transposable element family Heartbreaker into genic regions of maize. Proc Natl Acad Sci U S A. 97:1160-1165.

Zhang X, Jiang N, Feschotte C, Wessler SR. 2004. PIF- and Pong-like transposable elements: distribution, evolution and relationship with Tourist-like miniature inverted-repeat transposable elements. Genetics 166:971-986.

Zhong H, Zhou M, Xu C, Tang D-Q. 2010. Diversity and evolution of Pong-like elements in Bambusoideae subfamily. Biochem Syst Ecol. 38:750-758.

Zhou M-B, Lu J-J, Zhong H, Liu X-M, Tang D-Q. 2010. Distribution and diversity of PIFlike transposable elements in the Bambusoideae subfamily. Plant Sci. 179:257-266. 
Zwickl DJ. 2006. Genetic algorithm approaches for the phylogenetic analysis of large biological sequence datasets under the maximum likelihood criterion. $\mathrm{PhD}$ dissertation, The University of Texas at Austin. 


\section{General structure of Pong-like TE}

B

Oryza sativa $5166 \mathrm{bp}$ Accession BK000586

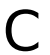

Australopyrum velutinum (5) Dasypyrum villosum (23) Hordeum chilense (6)

Triticum monococcum (16) Pseudoroegneria spicata (15) Brachypodium distachyon хм00356611 Oryza sativa AC132483.2 Zea mays EU972369

\section{D}

Australopyrum velutinum (5) Dasypyrum villosum (23) Hordeum chilense (6)

Triticum monococcum (16) Pseudoroegneria spicata (15)

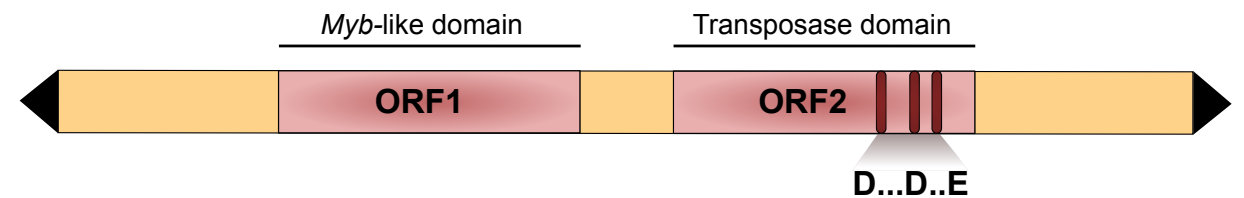

D...D..E

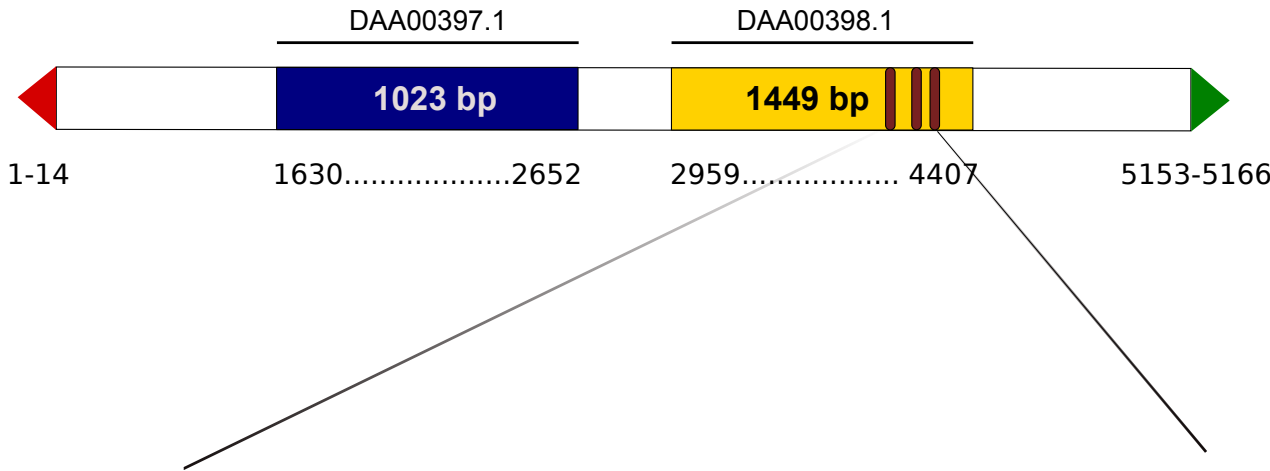

D

$\begin{array}{lllll}10 & 81 & 90 & 100 & 107\end{array}$

E

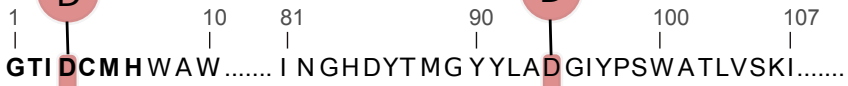

Thron

$142 \quad 162$

KAQEAVRKDVERAFG VLQSRF AI ACVLHNMIVEDE GTI DCM H WE W ...... VC GS QYNMG YYLVD GIYPEW AAFVKTI.......RRQE GARKDVER AFG V LQARF A I....... A CI LHNMIVEDE GTI DCM HWKW ....... I N GH HYNR G YYLAD GIYPQWL TLVKTI.......QT QENARKDVER VFG V LQSRWGI...... A CVLHNMIVEDE GTI DCM HW HW ....... VNE KEYQL G YYLVDGIYPEW AAFVKSI....... KHQE GAT KDVER AFG V LQARWS I....... A CI LHNMIVEDE GTI DCM HWT W ....... VN GHNYS MG YYLAD GIYPPW ATLVKTI.......QCQEAARKDVER DFG VLQKRF A I....... CCI LHNMIVEDE GSI DCM HW GW ....... VN GN NYT MG YYLADSIYPQW A TLVKTI .......KCQEAHRKDVER AFG VLQARF A I....... A CVI HNMIVEDE GSI DCM HWKW ....... I N GHDYMMG YYLAD GIYPSW ATFVKTI........ KAQEAI RKDVER AFG VLQARF A I....... ACVI HNMIVEDE GSLDCM HWRW ....... I N NHDYS MG YYLAD GIYPSW A TLVKTI ....... KAQEAARKDVER AFG VLQSRF A I...... A CI I HNMIVEDE

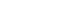

\begin{tabular}{l}
$\begin{array}{l}\text { HNMIVEDE } \\
\text { HNMIVEDE } \\
\text { HNMIVEDE } \\
\text { HNMIVEDE } \\
\text { HNMIVEDE }\end{array}$ \\
\hline (Pong_PSA 5' CACAACATGATRGTBGARGAC) \\
\hline (Pong SA 5' ACATGATRGTBGARGACGA)
\end{tabular}



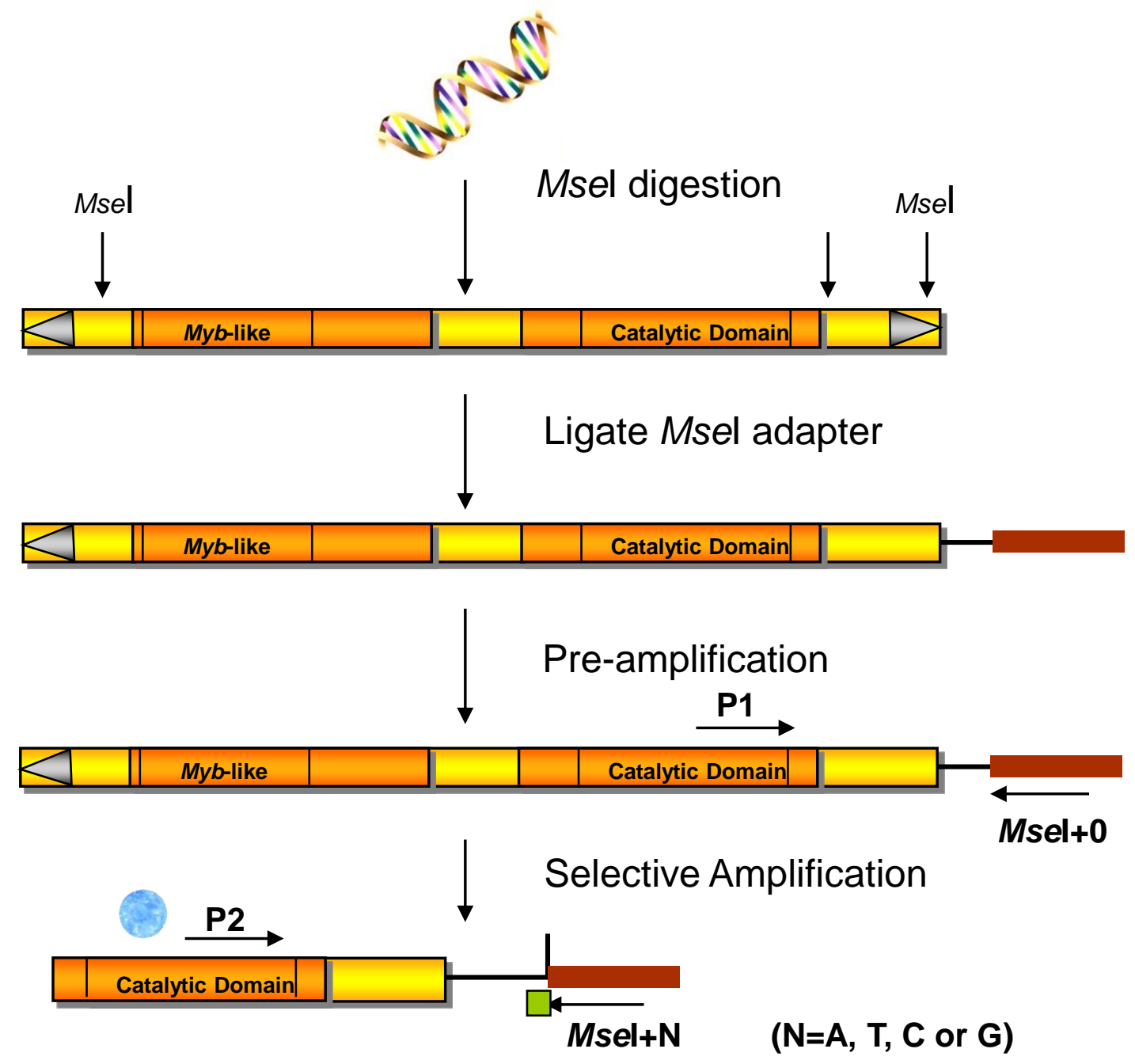


\section{Fignipe 3 R2}

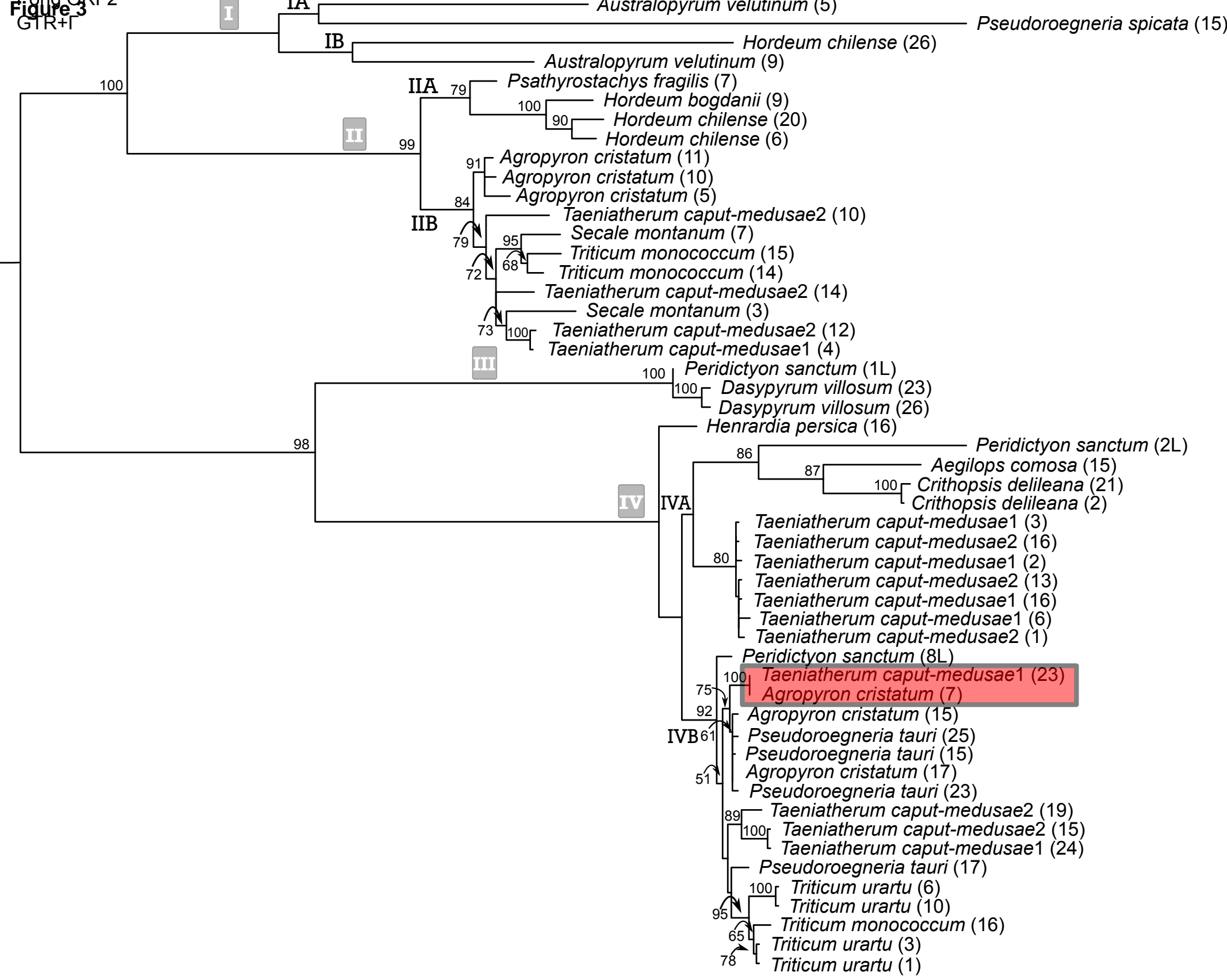


Brachypodium distachyon (1)

$m$ distachyon (1)
Hordeum chilense (26)

Oryza sativa (1) Zea mays

Australopyrum velutinum (5)

- Pseudoroegneria spicata (15)

$8 0 \longdiv { 1 }$ Brachypodium distachyon (2)

100 IIA $82-$ Psathyrostachys fragilis (7)

00 Hordeum bogdanii (9)

89 Hordeum chilense (20)

91- Agropyron cristatum (10)

IIB 94 - Agropyron cristatum (11)

Agropyron cristatum (5) Taeniatherum caput-medusae2 (10)

$84-92-$ Secale montanum $(7)$

6355 - Triticum monococcum (14)

Taeniatherum caput-medusam
Secale montanum (3)

[ Taeniatherum caput-medusae1

Taeniatherum caput-medusae2 (12)

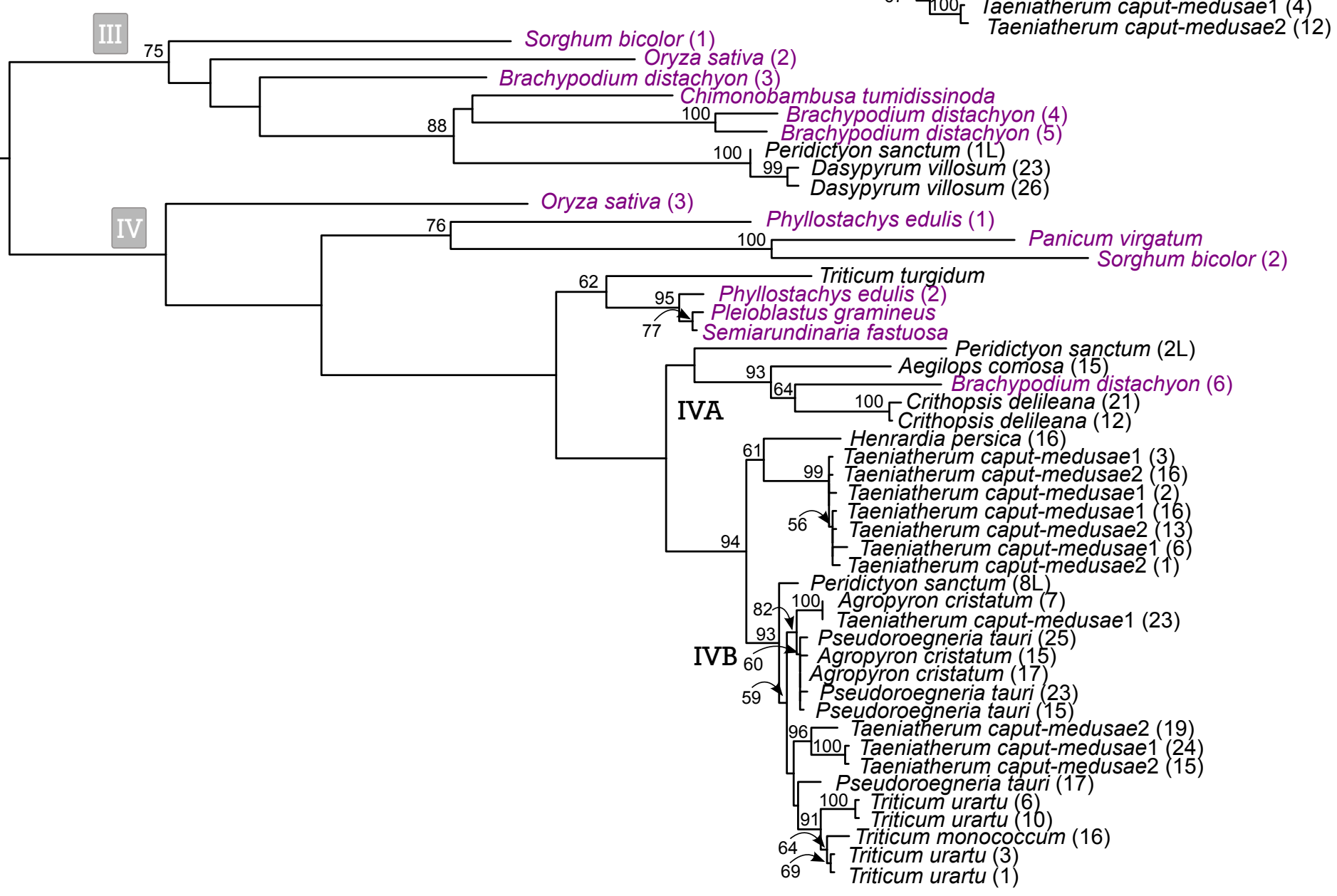


Figuthe 5reptor Pong TEs

$\mathrm{GTR}+\Gamma+\mathrm{I}$

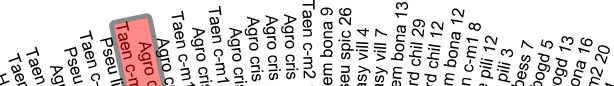

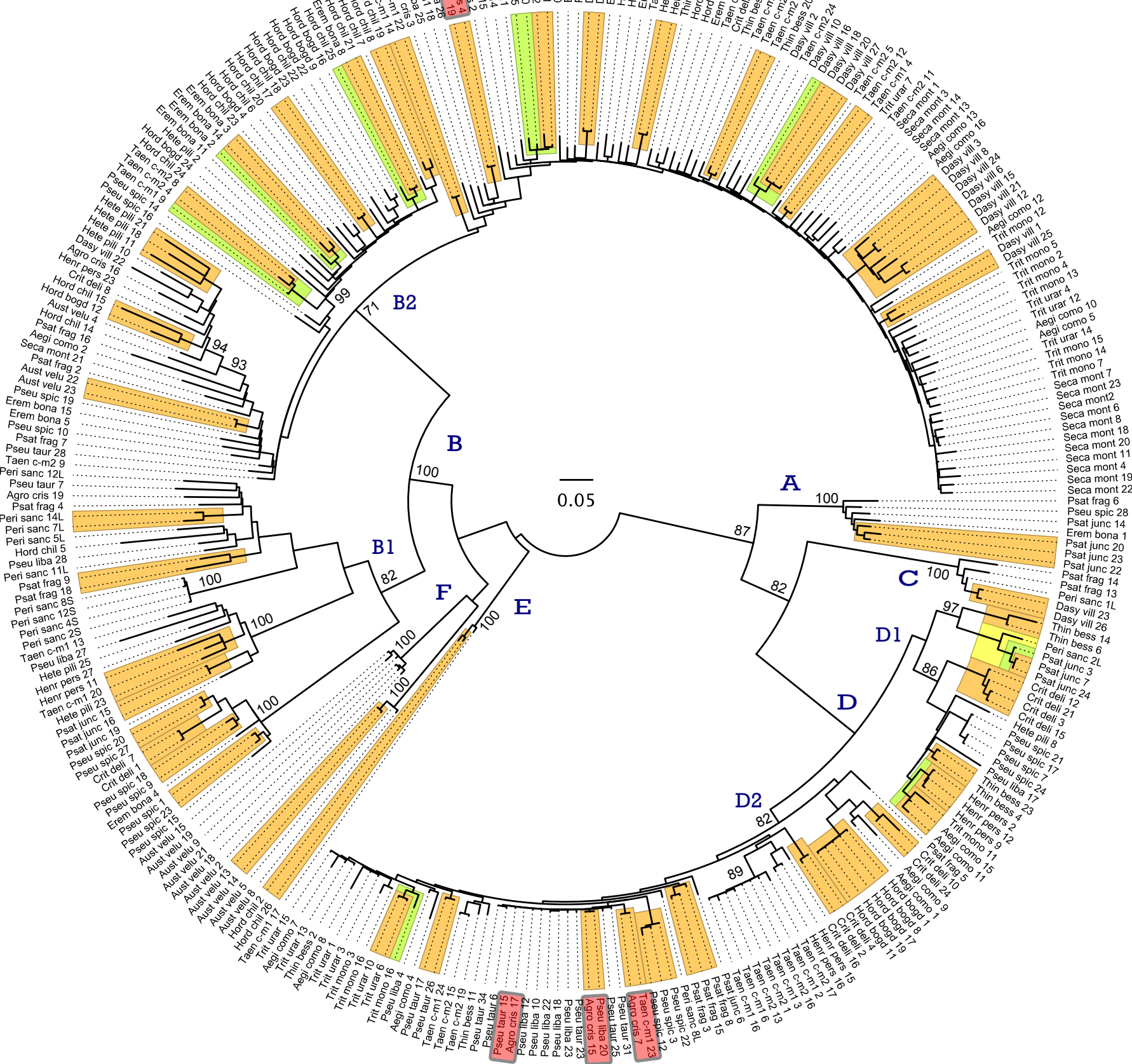



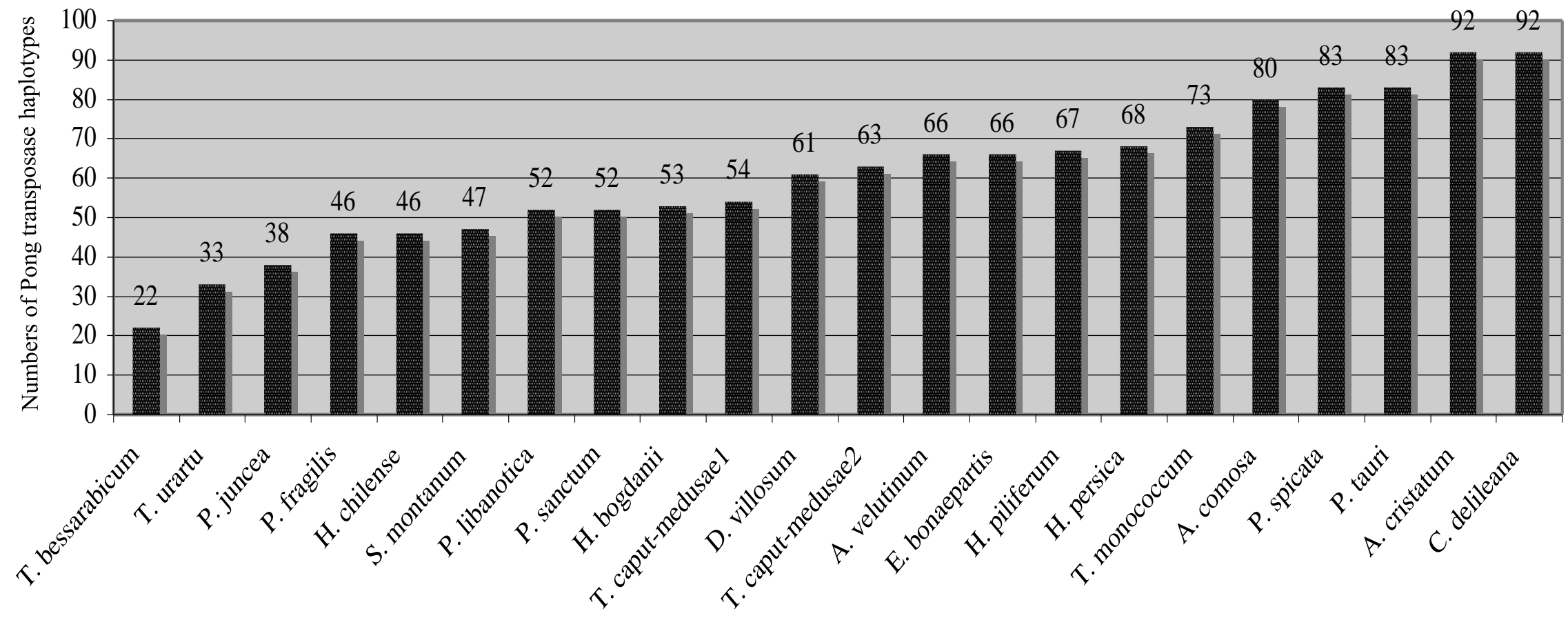


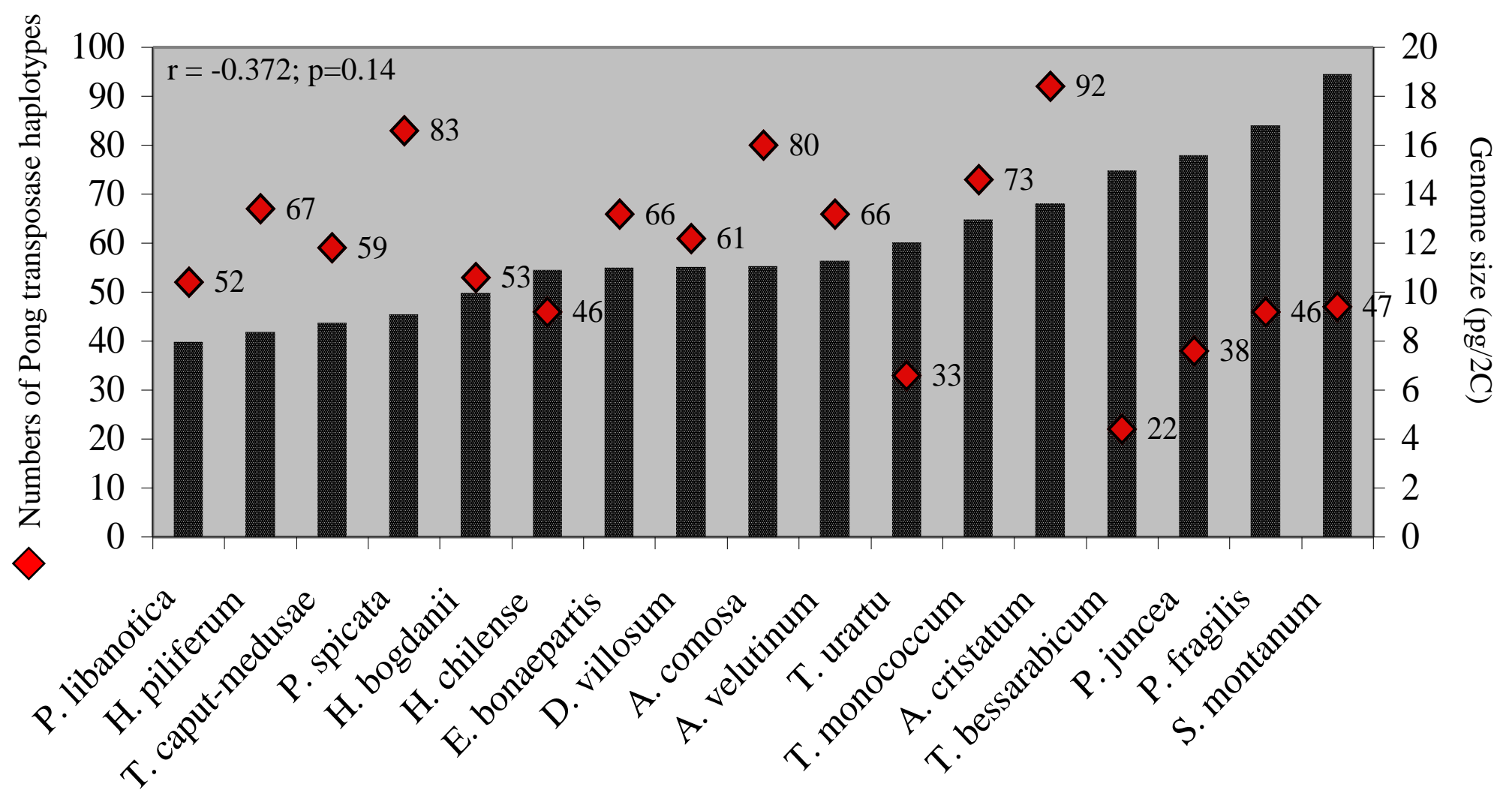




\section{FIGURE CAPTIONS}

Figure 1: Structure of Pong-like elements.

A) General structure of a Pong-like element with the corresponding ORFs.

ORF2 contains a "DDE" motif, a signature consisting of three conserved amino acids. The triangles represent TIRs and rectangles represent ORFs.

B) Schematic of the first identified Pong element from rice.

C) Comparison of the conserved transposase domain with the corresponding "DDE" motif from Brachypodium, Oryza, Zea, and five representative Triticeae genera. Primers used for ORF2 amplification are indicated by bold arrows.

D) Position of the HNMIVEDE conserved transposase domain. Primers used for transposon display are indicated by arrows. Pong_SA was labeled with 6-FAM fluorescent dye.

Figure 2: General procedure of the transposon display protocol as adapted from Casa et al. (2004). The technique consists of digesting genomic DNA with restriction endonuclease (MseI), ligating specific adapters at the extremities, and performing PCR, where one primer anchors in the area of the adapter and the other in the transposable element. P1 and P2 indicate the location of the internal primers used in the preselective and selective amplification. The primers used in this study were P1=MseI+0/Pong_PSA and $\mathrm{P} 2=$ Mse I+N/Pong_SA (see Materials and Methods), where $\mathrm{N}$ is a selective base (N=A,T,C, or G). P2 was fluorescently labeled with 6-FAM dye.

Figure 3: Phylogenetic analysis of the conserved transposase domain of 51 Pong-like transposase sequences from Triticeae with no frameshift and/or stop codons using the ML method (100 bootstraps, only values above 50\% are shown). The best ML tree was selected from 50 GARLI analyses under the GTR+G model of sequence evolution. Rectangle indicates identical transposase sequences from distinct genera. Numbers following taxon names distinguish individuals within species, and numbers in parentheses designate a specific cloned sequence from within individuals and are consistent among Figures 2-4. 
Figure 4: Phylogenetic analysis of 51 Pong-like transposase sequences from Triticeae and 20 additional transposase sequences from 9 Poaceae genera available in GenBank. All sequences contain no frameshift and/or stop codons. The best ML tree was selected from 50 GARLI analyses under the GTR+G model of sequence evolution. Numbers above branches show ML bootstrap support (100 bootstraps, only BS values above 50\% are displayed). Numbers following taxon names distinguish individuals within species, and numbers in parentheses designate a specific cloned sequence from within individuals and are consistent among Figures 2-4.

Figure 5: Phylogenetic analysis of 297 Pong-like transposase sequences from Triticeae using the ML method (100 bootstrap replicates). The best ML tree was selected from 50 GARLI analyses under the GTR+G+I model of sequence evolution. Rectangles indicate identical and near identical transposase sequences from distinct genera. Shaded rectangular boxes along branches represent clades with BS above $90 \%$. BS values above $50 \%$ are displayed with numbers. Species names are displayed with the first four letters of the genus, followed by the first four letters of the species name. Numbers following taxon names distinguish individuals within species, and numbers in parentheses designate specific cloned sequences from within individuals and are consistent among Figures 2-4.

Figure 6: Numbers of Pong transposase haplotypes from 22 diploid Triticeae samples.

Figure 7: Comparison between Pong transposase diversity and genome size for 18 Triticeae accessions. 
Table 1: Triticeae samples included in Pong analyses.

\begin{tabular}{lccc}
\hline Species name & $\begin{array}{c}\text { Sample source and } \\
\text { reference number }\end{array}$ & Genome & $\begin{array}{c}\text { 2C DNA } \\
\text { amount (pg) }\end{array}$ \\
\hline Aegilops comosa Sibth. \& Smith & USDA/G602 & $\mathrm{M}$ & 11.06 \\
Agropyron cristatum (L.) Gaertn. & USDA/PI 279802 & $\mathrm{P}$ & 14.26 \\
Australopyrum velutinum (Nees) B.K.Simon & USDA/D 2873-2878 & $\mathrm{W}$ & 11.28 \\
Crithopsis delileana (Schult.) Roshev. & USDA/H 5562 & $\mathrm{K}$ & $\mathrm{n} / \mathrm{a}$ \\
Dasypyrum villosum (L.) P.Candargy & USDA/D 2990 & $\mathrm{V}$ & 11.04 \\
Eremopyrum bonaepartis (Spreng.) Nevski & USDA/PI 227344 & $\mathrm{F}$ & 11.00 \\
Henrardia persica (Boiss.) C.E.Hubb & USDA/H 5556 & $\mathrm{O}$ & $\mathrm{n} / \mathrm{a}$ \\
Heteranthelium piliferum (Banks \& Sol.) & USDA/PI 402352 & $\mathrm{Q}$ & 8.36 \\
Hochst. & USDA/PI 531762 & $\mathrm{I}$ & 9.96 \\
Hordeum bogdanii Wilensky & USDA/PI 531781 & $\mathrm{I}$ & 10.90 \\
Hordeum chilense Roem. \& Schult. & USDA/KJ 248 & $\mathrm{Xp}$ & $\mathrm{n} / \mathrm{a}$ \\
Peridictyon sanctum (Janka) Seberg, Fred., \& & & & \\
Baden & USDA/PI 343192 & $\mathrm{Ns}$ & 16.8 \\
Psathyrostachys fragilis (Boiss.) Nevski & USDA/PI 206684 & $\mathrm{Ns}$ & 15.6 \\
Psathyrostachys juncea (Fisch.) Nevski & USDA/PI 228391 & $\mathrm{St}$ & 7.96 \\
Pseudoroegneria libanotica (Hack.) & & & \\
D.R.Dewey & USDA/D 2844 & $\mathrm{St}$ & 9.10 \\
Pseudoroegneria spicata (Pursh) Á.Löve & USDA/PI 401319 & $\mathrm{St}$ & $\mathrm{n} / \mathrm{a}$ \\
Pseudoroegneria tauri (Boiss. \& Balansa) & & & \\
Á.Löve & & $\mathrm{R}$ & 18.90 \\
Secale montanum Guss. & USDA/T 36554 & Ta & 8.76 \\
Taeniatherum caput-medusae (L.) Nevski & USDA/PI 208075 & Ta \\
Taeniatherum caput-medusae & USDA/PI 283240 & Ta & - \\
Thinopyrum bessarabicum (Săvul. \& Rayss) & USDA/PI 531711 & $\mathrm{J}$ & 14.96 \\
Á.Löve & & & \\
Triticum monococcum L. & USDA/PI 221413 & $\mathrm{A}$ & 12.96 \\
Triticum urartu Tumanian ex Gandilyan & Morrison s.n. & $\mathrm{Au}$ & 12.04 \\
\hline
\end{tabular}

\footnotetext{
${ }^{a}$ data from RBG Kew Angiosperm DNA $C$-values database; Bennett and Leitch, 2012
}

${ }^{\mathrm{b}} \mathrm{n} / \mathrm{a}$ : not available 
Table 2: List of 20 additional Poaceae samples included in Pong phylogeny

\begin{tabular}{|c|c|c|c|}
\hline Species name & Subfamily & Tribe & $\begin{array}{l}\text { GenBank } \\
\text { accession }\end{array}$ \\
\hline $\begin{array}{l}\text { Brachypodium distachyon (L.) } \\
\text { P.Beauv. (1) }\end{array}$ & Pooideae & Brachypodieae & XM003566116 \\
\hline Brachypodium distachyon (2) & & & XM003559519 \\
\hline Brachypodium distachyon (3) & & & XM003570851 \\
\hline Brachypodium distachyon (4) & & & XM003581389 \\
\hline Brachypodium distachyon (5) & & & XM003565470 \\
\hline Brachypodium distachyon (6) & & & XM003572489 \\
\hline $\begin{array}{l}\text { Chimonobambusa tumidissinoda } \\
\text { J.R.Xue \& T.P.Yi ex D.Ohrnb. }\end{array}$ & Bambusoideae & Arundinarieae & GU350853 \\
\hline Oryza sativa L. (1) & Ehrhartoideae & Oryzeae & AC132483.2 \\
\hline Oryza sativa (2) & & & NM001073509 \\
\hline Oryza sativa (3) & & & AK106574 \\
\hline Panicum virgatum $\mathrm{L}$. & Panicoideae & Paniceae & AC243243 \\
\hline $\begin{array}{l}\text { Phyllostachys edulis (Carrière) } \\
\text { J.Houz. (1) }\end{array}$ & Bambusoideae & Arundinarieae & GU350822 \\
\hline Phyllostachys edulis (2) & & & GU350842 \\
\hline $\begin{array}{l}\text { Pleioblastus gramineus (Bean) } \\
\text { Nakai }\end{array}$ & Bambusoideae & Arundinarieae & GU350863 \\
\hline $\begin{array}{l}\text { Semiarundinaria fastuosa } \\
\text { (Mitford) Makino }\end{array}$ & Bambusoideae & Arundinarieae & GU350852 \\
\hline Sorghum bicolor (L.) Moench (1) & Panicoideae & Andropogoneae & XM002442282 \\
\hline Sorghum bicolor (2) & & & XM002449012 \\
\hline Triticum aestivum $\mathrm{L}$. & Pooideae & Triticeae & FN564434 \\
\hline Triticum turgidum $\mathrm{L}$. & Pooideae & Triticeae & EF540321 \\
\hline Zea mays L. & Panicoideae & Andropogoneae & EU97236 \\
\hline
\end{tabular}


Table 3: Sequences of primers and adapters used in Pong transposon display

\begin{tabular}{ll}
\hline Adapter & Sequence \\
\hline MseI adapter 1 & 5' GACGATGAGTCCTGAG \\
MseI adapter 2 & 5' TACTCAGGACTCAT \\
\hline Preselective Amplification & Sequence \\
\hline MseI & 5' GACGATGAGTCCTGAGTAA \\
Pong_PSA & 5' CACAACATGATRGTBGARGAC \\
\hline Selective Amplification & Sequence \\
\hline MseI+A & 5' GACGATGAGTCCTGAGTAAA \\
$M s e I+T$ & 5' GACGATGAGTCCTGAGTAAT \\
$M s e I+C$ & 5' GACGATGAGTCCTGAGTAAC \\
$M s e I+G$ & 5' GACGATGAGTCCTGAGTAAG \\
Pong_SA_6FAM & 5' ACATGATRGTBGARGACGA \\
\hline
\end{tabular}


